lecionadas podem ser editadas no monitor ou impressas. E possível editar apenas uma parte da ficha.

\section{DESCRIÇÃO DA ESTAÇÃO DE CONSULTA}

\author{
MICHEL LENCI \\ Diretor do Centre d'Automatique \\ et d'Informatique \\ École Normale Supérieure des \\ Mines de Paris
}

O aparelho de interrogaçāo do banco de dados de imagens foi concebido no Centre d'Automatique et d'Informatique da Ecole Normale Supérieure des Mines de Paris. Ele se compõe de um microcomputador, de um termi- 1 nal e de seu monitor.

O microcomputador é ligado por meio de um modem ao computador central no qual estão estocados os bancos de dados. Seu papel é duplo: ele conserva localmente as respostas enviadas pelo computador central e controla o videoleitor, oferecendo ao usuário uma série de comandos para percorrer as respostas e obter no monitor as vistas correspondentes (Figura $\mathrm{n}^{0}$ 1).

Num primeiro momento o microcomputador funciona no modo "transparente", isto é, tudo que é digitado no terminal é enviado ao computador central. Inversamente, tudo que vem do computador central é enviado à tela do terminal. $O$ usuário pode assim conduzir uma sessão normal. Ele pode, particularmente, submeter uma questão aos bancos de dados. O computador responde então enviando o texto dos documentos pertinentes. $O$ microcomputador que vigia o fluxo de dados detecta primariamente o fluxo de respostas. Ele passa então a um segundo modo de funcionamento, dito modo "local".

No modo local, o fluxo proveniente do computador central - isto é, as respostas à questão colocada - não é mais dirigida para a tela do terminal, mas é estocada na memória do microcomputador. $O$ usuário está então informado que pode começar a consultar os documentos recebidos, enquanto outros continuam a chegar.

Ele dispóe para isto de um certo número de comandos que lhe permitem obter na tela os documentos recebidos

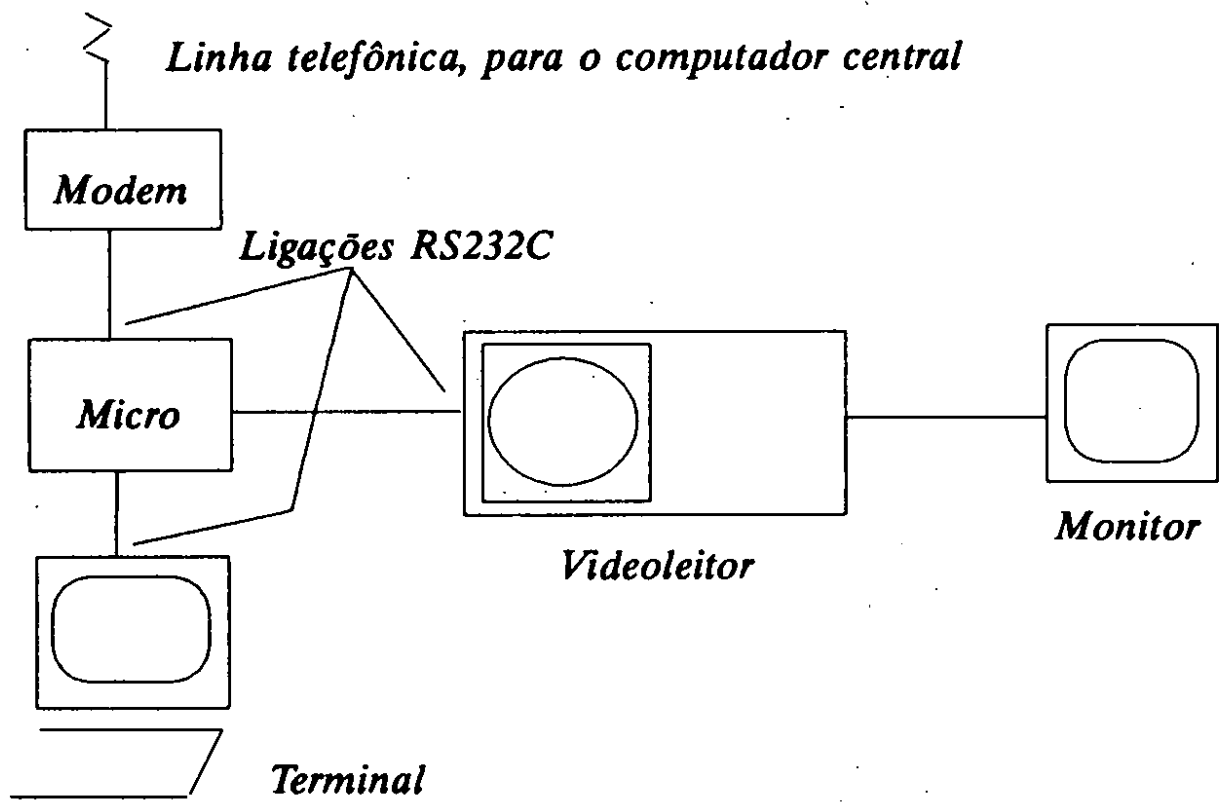

Figura $n^{\circ}$ 1: Esquema das conexōes da estação de consulta 
e no monitor as vistas correspondentes a cada um deles.

Um mesmo documento pode ser ilustrado por várias vistas. As vistas são indicadas pelo seu número de registro no videodisco. Este número figura no texto dos documentos.

Existe igualmente um modo de exibição automático no qual as vistas se sucedem sem a intervenção do usuário, bem como os documentos. A cadência desse modo de exibição é regulável e ela pode ser momentaneamente interrompida (comando PAUSA). O percurso pode ser feito para a frente ou para trás.

Um documento pode ser chamado pelo seu número de identificação. Uma lista de explicaçōes é acessível por um comando de auxílio.

A qualquer momento o usuário pode passar para o modo transparente sem perder os documentos recebidos. Ele pode assim interromper a sessão com o computador central após a recepção do último documento ou colocar uma nova questão cujas respostas virão, de acordo com a sua escolha, se acrescentar àquelas que recebeu anteriormente ou substituí-las.

Este logicial de controle foi concebido em uma ótica do tipo : caixa de telecomando (controle remoto), isto é, a quase totalidade dos comandos é dada pela ação direta no teclado. $O$ conjunto verifica-se de uma manejo cômodo e rapidamente apreensível para os novos usuários.

O microcomputador foi construído especialmente para esta aplicação. Esta solução foi preferível ao emprego de um microcomputador padrão em razão das performances necessárias: nenhum dos caracteres que chegam por linha deve ser perdido, garantindo-se uma exibição rápida na tela (até 2000 caracteres por segundo). $O$ custo do aparelho é competitivo, já que ele se situa ao redor dos 5000 francos. $O \mathrm{mi}$ - crocomputador possui uma memória de 56 Koctets para a estocagem dos documentos, o que permite manter a maioria das respostas às questōes comuns.

As extensões abordadas referentes à união de um tipo de bloco de notas onde o usuário poderia registrar os números dos documentos que lhe interessam e fazer uma seleção a partir dos documentos recebidos para trabalhar apenas com um subconjunto deles.

O microcomputador e seu logicial são facilmente adaptáveis ao controle de outros modelos de videoleitores bem como ao diálogo com outros logiciais de gestão de bancos de dados.

\section{Referências Bibliográficas}

1. BALMELLE, Catherine et alii. Le Décor Géometrique de la Mosaïque Romaine. Paris, 1985.

2. BAUZOU, Claude. Interrogation d'une base de données auto-structurante SIGMINI. Tese de $3^{\circ}$.Ciclo, Faculté d'Orsay, 1983.

3. BRISBOIS, Charline. Méthode de structuration des informations et compositions des dictionnaires pour les banques d'information technicoéconomique et technique. Bruxelles, Union Minière, rapport interne, 1975.

4. CACALY, Serge. Images au Présent du Passé: Vidéodisque et Archéologie. Brises, $\mathrm{n}^{\circ}$ 6, mars 1985, p. 39-40.

5. FOURMONT, Martine H. Introduction, présentation materielle du volume et remarques d'utilisation. In Catalogue Topographique VI, Italie 2, Rome, Musée National Etrusque de Villa Giulia, 2. Paris, Centre de Documentation Photographique et Photogrammétrique. (a ser publicado).

6. GINOUVES, René e GUIMIER-SOR- 
BETS, Anne-Marie. La Constitution des Données en Archéologie Classique. Paris, 1978.

7. GUIMIER-SORBETS, Anne-Marie. La Mosaique Grecque: Deux Approches Documentaires. In Panorama 1983 des Traitements Automatisés en Archéologie. Valbonne, p. 9-30.

8. GUIMIER-SORBETS, Anne-Marie. Une Banque de Données sur la Mosaïque dans le monde Grec, des Origines à la Fin de l'Époque Hellénistique. In III Colloque International sur la Mosaique Antique. Ravenne, 1984, p. 515-524.

9. GUIMIER-SORBETS, Anne-Marie. Banques de Données Documentaires en Archéologie Classique: Quelques Réponses aux Problèmes Posés par leur Constitution. Informatique et Sciences Humaines, $\mathrm{n}^{\mathbf{2}}$ especial Informatique et Archéologie, ne 59-60, 1984, p. 69-93.

10. GUIMIER-SORBETS, Anne-Marie. La Photothèque du Centre de Recherche sur la Mosaïque - Consti- tution d'une Banque de Données Documentaire pour la Consultation Automatisée. In IV Colloque International sur l'Étude de la Mosaïque Antique, Trèves, 8-14 Août 1984. (texto a ser publicado nas Actes).

11. GUIMIER-SORBETS, Anne-Marie. Une Banque de Données pour Automatiser la Consultation de la Photothèque du CDPP. Principes d'Analyse et Système d'Exploitation Documentaire. In Catalogue Topographique VI, Italie 2, Rome, Musée National Etrusque de Villa Giulia, 2. Paris, Centre de Documentation Photographique et Photogrammétrique. (a ser publicado).

12. LENCI, Michel. Les Bases de la Codification Sémantique. École des Mines de Paris. DCI 265.03.74, 1974.

13. MORDINI, Patrick. SIGMINI, Un Modèle Auto-Structurant de Base de Données. Tese de $3^{\circ}$ ciclo, I.P., Paris VI, 1979. 